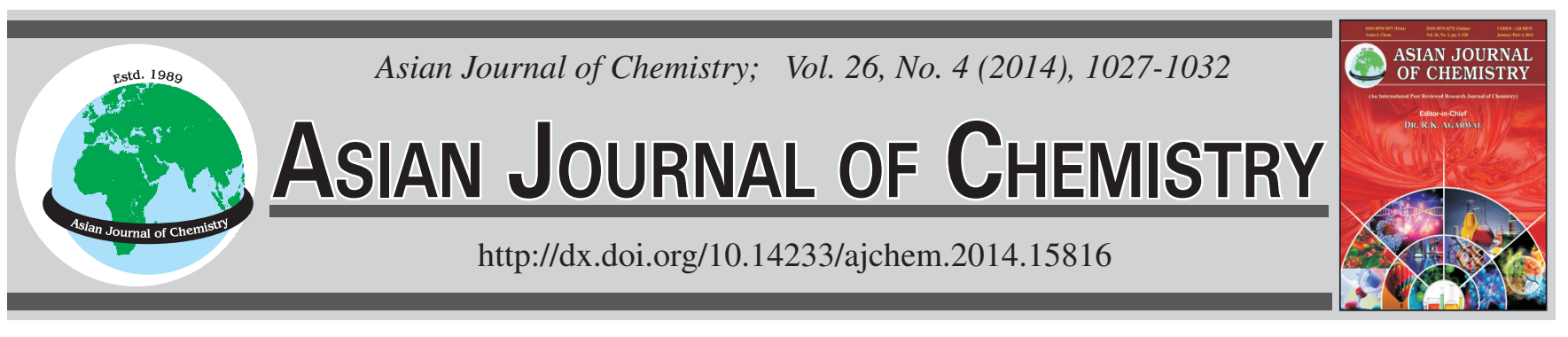

\title{
Thermal Analysis of Long-Term Storage Lignite in Oxygen-Enriched Air
}

\author{
Xiangyun Chen, Yongfeng Zhang*, Qiancheng Zhang and Quan Zhou
}

Inner Mongolia University of Technology, Hohhot 010051, P.R. China

*Corresponding author: E-mail: environzyf@sina.com; lzg05006@163.com

The combustion behavior of fresh lignite and long-term storage lignite from the same region were assessed in $\mathrm{O}_{2} / \mathrm{N}_{2}$ background gases by using thermogravimetric analyzer. The oxygen mole fraction is in the range of 21-80\%. The results show that the combustion ability of long-term storage lignite is weaker than the fresh one. The storage lignite almost unable to ignite when the oxygen content per cent is $21 \%$ and can't burn out before $30 \% \mathrm{O}_{2}$ atmosphere. While the fresh sample can burn out completely in each atmosphere. Oxygenenriched atmosphere improve the combustion and ignition capacity of the long-term storage lignite, especially the partial pressure of $\mathrm{O}_{2}$ above $40 \%$.

Keywords: Oxygen-enriched combustion, Long-term storage lignite, Fresh lignite, Thermal analysis.

\section{INTRODUCTION}

Combustion is fundamental process to our industrial society. A high proportion of the electricity produced indeed in the world is based on pulverized coal fired utility boilers and a considerable amount of this is from the combustion of coal. Coal is set to grow in importance and become the predominant fuel for the industry, transport and domestic requirements for at least the next 50 years or more ${ }^{1}$. It is important for energy producer to buy and burn low cost fuel depending on the market opportunities and minimize their cost to remain competitive while respecting to environmental constrains.

When lignite is stored under ordinary conditions, progressive change take place in its chemical and physical properties ${ }^{2}$. These changes are largely caused by the reaction of atmospheric oxygen with lignite ${ }^{3}$. Oxidation is responsible for the major compositional and structural changes and causes deterioration in the technological properties of coal ${ }^{4}$. Wang et al. ${ }^{5}$ argued that coal oxidation at low temperatures (i.e. below $100{ }^{\circ} \mathrm{C}$ ) is a complicated process and involves four phenomena: oxygen transport to the surfaces of coal particles, chemical interaction between coal and $\mathrm{O}_{2}$, release of heat and emission of gaseous products. The diversity of chemical composition, physical properties (such as heat capacity and thermal conductivity) and porous structure of coal enhances the complexity of this phenomenon. Coal oxidation affects the molecular structure of coal and alters the mass and elemental composition of $\mathrm{coal}^{5}$, coal may lose up to $15 \%$ of the calorific value and the coking properties of gas-making coal may be destroyed ${ }^{5-8}$.
The characteristic of coal oxidation in low temperature have been extensively reported by a number of workers. Wang et al. ${ }^{9}$ studied the coal oxidation by IR in different low temperature, The intensity of peaks about carbonyl groups increased. Wang et al. ${ }^{10}$ showed that carboxyl and ether groups are the main oxygen containing moieties in oxidized coal. Nugroho et al. ${ }^{11}$ found that the low rank coals dependence weakly on the particle size of the coals compared with the high rank coals. Various functional groups existing on the surface of coal serve as adsorption sites for oxygen and moisture in the air. In particular, since low rank coal, with its low carbonization degree, has many functional groups on its surface by nature. It more easily oxidizes even at low temperatures compared to high rank coal.

During storage and transportation of lignite, it will undergo oxidation and moisture evaporation and readsorption. Although both the physical desorption and the experimental procedure affected the rates at the early stage of these experiments, the rates of production of carbon oxides in the leveling-off region are evidently higher for an unoxidized coal ${ }^{12}$. The liability of oxidation of the lignite was increased with decreasing particle size, increasing moisture content of the coal and decreasing humidity of the air ${ }^{13}$.

With the development of low cost of oxygen making technology, oxygen-enriched combustion technology is gradually developing. There exit a considerable number of studies carried out for the investigation of combustion behavior of fresh coals in oxygen-enriched environment by TGA ${ }^{14-16}$. This concluded that oxygen-enriched atmosphere can substract burning time 
TABLE-1

PROXIMATE AND ULTIMATE ANALYSES OF FRESH HUOLINHE LIGNITE AND STORAGE HUOLINHE LIGNITE

\begin{tabular}{|c|c|c|c|c|c|c|c|c|c|c|}
\hline & \multicolumn{4}{|c|}{ Proximate [wt. \%] } & \multicolumn{5}{|c|}{ Ultimate [wt. \%, DAF] } & \multirow{2}{*}{$\mathrm{CV}\left[\mathrm{kJ} \mathrm{kg}^{-1}\right]$} \\
\hline & $\mathbf{M}_{\mathrm{ad}}$ & $\mathrm{V}_{\mathrm{d}}$ & $\mathrm{FC}_{\mathrm{d}}$ & $\mathrm{A}_{\mathrm{d}}$ & $\mathrm{C}$ & $\mathrm{H}$ & $\mathrm{O}$ & $\mathrm{N}$ & $\mathrm{S}_{\mathrm{t}}$ & \\
\hline Fresh & 8.32 & 42.18 & 43.42 & 14.40 & 73.06 & 4.83 & 19.15 & 1.35 & 1.61 & 23.64 \\
\hline Storage & 12.38 & 46.46 & 38.22 & 16.80 & 69.82 & 5.12 & 22.61 & 2.03 & 1.72 & 20.18 \\
\hline
\end{tabular}

and improve combustion activity of the coal. However, an investigation of oxygen-enriched combustion characteristic of storage lignite is not available to date.

Lignite-coal regions of Inner Mongolia Province in China constitute $75 \%$ of the whole province ${ }^{17}$. Now the lignite mainly used in electric power stations near coal-mines for its oxidizability when were stored a period of time or long distance transportation. It is necessary to discuss the combustion property of the long-term storage lignite to expand its use.

We report here on the effects of oxygen concentration on combustion characteristics of long-term storage lignite. The aim is to gather comprehensive data to overcome the disadvantage for combustion of lignite in storage and transportation.

\section{EXPERIMENTAL}

Lignite was supplied from Huolinhe (HL) opencast coal mine, the northeast of Inner Mongolia in China. The sample was divided into two parts, One part was tested once, the other was stored in air for one month. The sample was dried, ground and sieved to make the particle size is less than $180 \mu \mathrm{m}$ and then placed in a desiccator in reserve.

A 5E-CHN2000 and 5E-MAG6700 element analyzer and a 5E-IRS3000 sulfur analyzer were used in proximate and ultimate analyses. Calorific value of the sample determined by using a 5E-KCIV. Results are presented in Table- 1 .

The equipment used in this study was a Thermal Analyzer (Netzsch-STA 409pc) which has the capable of simultaneous determination of the differential scanning calorimetry (DTA) and thermogravimetry (TG) profiles of samples. The TG/DTA curves were obtained using the following experimental conditions: Flow rate: $80 \mathrm{~mL} \mathrm{~min}^{-1}$; sample size: $10 \mathrm{mg}$; heating rate: $10{ }^{\circ} \mathrm{C} \mathrm{min}^{-1}$; temperature range: $30-1000{ }^{\circ} \mathrm{C}$. Combustion tests were performed in $\mathrm{N}_{2} / \mathrm{O}_{2}$ mixtures (the volume fraction of $\mathrm{O}_{2}$ is $21 \%, 30 \%, 40 \%, 60 \%$ and $80 \%$ ).

\section{RESULTS AND DISCUSSION}

FTIR profiles of storage lignite and fresh lignite: Many workers $^{18,19}$ investigated the coal oxidized in low temperature by FTIR spectrum technology which can observe the change of functional groups on the coal surface. FTIR spectrum of the lignite sample is given in Fig. 1. The absorptions at 3730 and $3620 \mathrm{~cm}^{-1}$ are due to intermolecular and weakly $\mathrm{H}$ bonded $\mathrm{OH}$ because of water of crystallization in lignite. The two absorptions are not appear in the storage lignite. Fresh lignite shows the presence of free hydroxyl group, intermolecular $\mathrm{H}$ bonded $\mathrm{OH}$, phenolic hydroxyl group, alcoholic hydroxyl group with several absorption peaks, but the absorption peak of hydroxyl groups disappeared or only one leaved of storage lignite. Literature ${ }^{19}$ revealed that the free hydroxyl group and intermolecular $\mathrm{H}$ bonded $\mathrm{OH}$ disappeared for the oxidation of

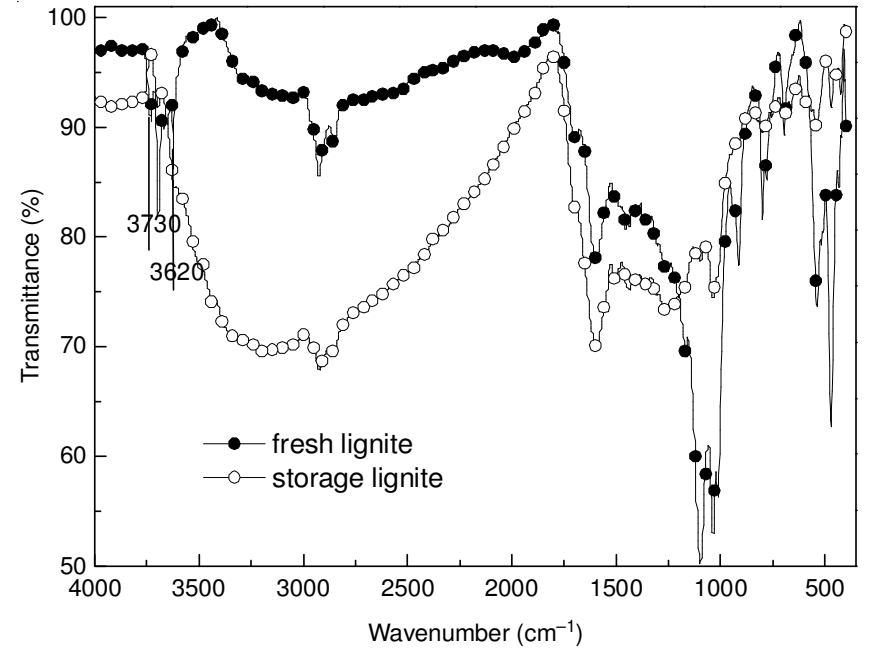

Fig. 1. FTIR spectrum of Huolinhe fresh lignite and Huolinhe storage lignite

lignite. $1380 \mathrm{~cm}^{-1}$ and flexible hydroxyl absorbance at 3690 $\mathrm{cm}^{-1}$ and $3616 \mathrm{~cm}^{-1}$. The carbonyl absorbance at $1700 \mathrm{~cm}^{-1}$ formed and then disappeared and, as well, the ether absorbance at $1110-1330 \mathrm{~cm}^{-1}$ gradually reduced. Acid amides, a problem for oxidation, were formed at $1660-1650 \mathrm{~cm}^{-1}$ in the anthracite. Low-rank coal such as lignite has many active side chains and functional groups easily fall off and are therefore easy to oxidize. The FTIR comparation of fresh lignite and storage lignite in Fig. 1 indicate that the surface of the storage lignite has been oxidized during storage.

TG profiles of storage lignite and fresh lignite: Combustion tests of fresh lignite and storage lignite were carried out in $\mathrm{O}_{2} / \mathrm{N}_{2}$ mixture environment with six conditions. Fig. 2 displays the TG profiles of the fresh lignite and the storage lignite in oxygen-enriched combustion condition. Both fresh lignite TG curves and storage lignite curves show three combustion stages, the initial weight loss take place due to moisture release between 30 and $150{ }^{\circ} \mathrm{C}$ for all fuel samples and combustion environment. The initiation of the combustion process is not affected by oxygen concentration level. But at higher temperature, in the second stage between 150 to $500{ }^{\circ} \mathrm{C}$, elevated oxygen levels in combustion environment shifts the weight loss curves to lower temperature zone. Which is associated with devolatilization and char burning within the temperature range. Over $500{ }^{\circ} \mathrm{C}$ is the third temperature region, it is the burning out region with no weight loss of the curves and is not affected by the oxygen level.

Both the TG curve shift to the low temperature area with the content of oxygen increase. Fig. 2 (a) shows that the mass of combustion residual solid different in each atmosphere and become decreased with the content of oxygen increasing. The mass of combustion residual solid are summarized in Table-2. 

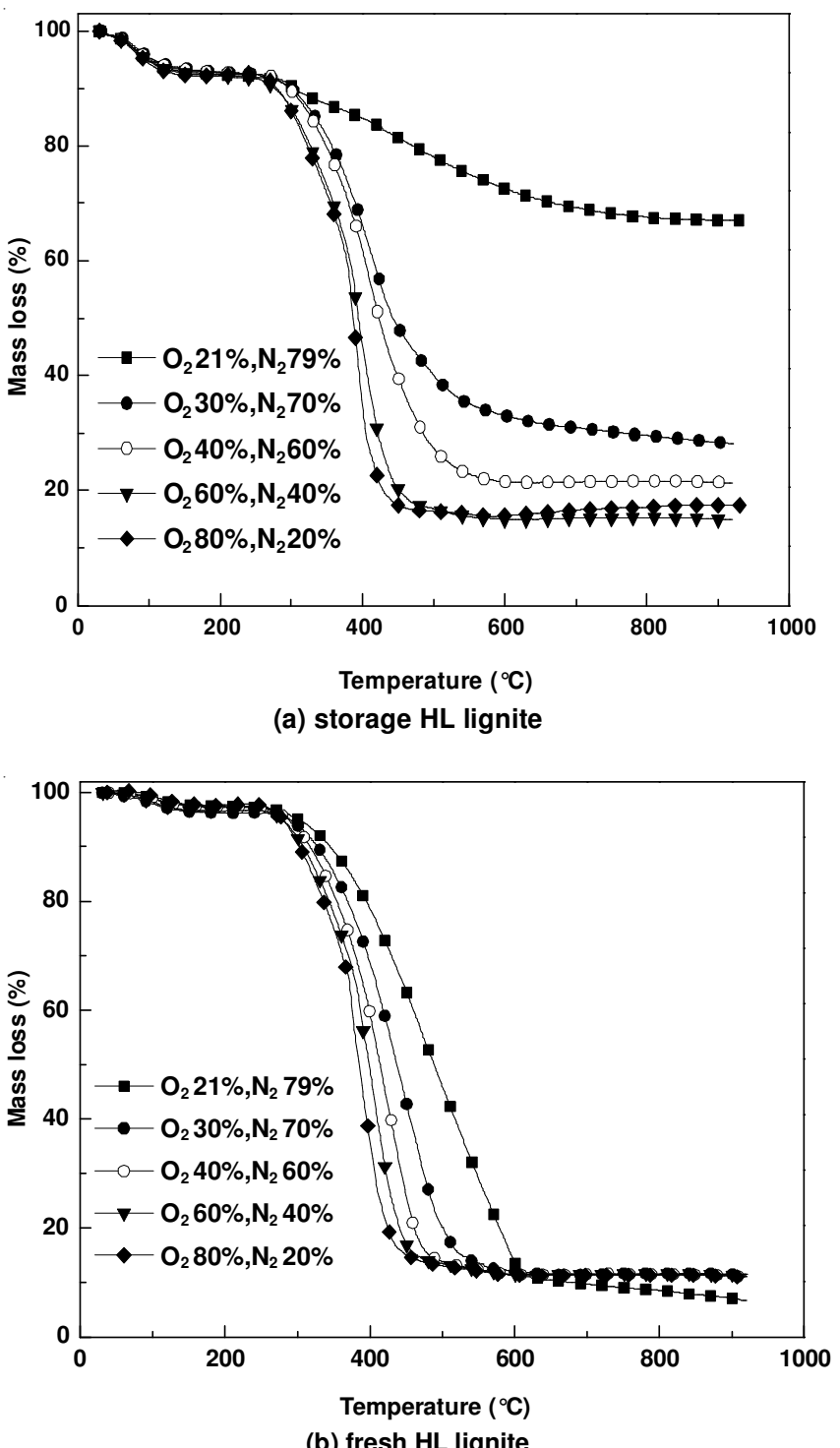

Fig. 2. TG profiles of Huolinhe lignite and Huolinhe fresh lignite in oxygenenriched atmosphere

TABLE-2

MASS OF RESIDUAL SOLID IN DIFFERENT ATMOSPHERE OF STORAGE LIGNITE

\begin{tabular}{llllll}
\hline & & \multicolumn{5}{c}{$\mathrm{O}_{2}: \mathrm{N}_{2}$} \\
\hline residual solid & $21: 79$ & $30: 70$ & $40: 60$ & $60: 40$ & $80: 20$ \\
[wt. \%] & 66.94 & 28.14 & 21.32 & 14.93 & 15.53 \\
\hline
\end{tabular}

It is evident from Table-2, that the mass of combustion residual solid is $66.94 \%$ in $21 \% \mathrm{O}_{2} / 79 \% \mathrm{~N}_{2}$ atmosphere higher about $51 \%$ of the incombustible composition in the sample. when the content of oxygen over $40 \%$, the mass of combustion residual solid near the proportion of incombustible composition in the sample which is according with Table-1. At the same time, the black solid is found in the combustion residues when the content of oxygen below $40 \%$. It is suggested that the combustible composition of samples are not burned out.

The mass of combustion residual solid are essentially equal in each atmosphere showed in Fig. 2 (b). The values near to the ash content showed in Table-1 and can observe the yellowish white solid of the combustion residue. which indicate that the fresh lignite is burned out in each atmosphere.
The comparation the TG profiles of fresh lignite and storage lignite in each atmosphere are shown in Fig. 3 a-e. The rate of mass loss is closed to the fresh lignite until the storage lignite burn stop in $30 \%, 60 \%$ and $80 \% \mathrm{O}_{2}$ atmosphere. The fresh lignite burn faster than the storage one in $40 \% \mathrm{O}_{2}$ atmosphere. It shows that particle pressure of $\mathrm{O}_{2}$ plays a major role in storage lignite combustion. $40 \% \mathrm{O}_{2}$ is the point of division for storage lignite. The storage lignite only burned a part when the particle pressure of $\mathrm{O}_{2}$ below $40 \%$ and the combustion rate similar with the fresh lignite in the combustion area. The curve of storage lignite is coincide with the curve of fresh lignite and the storage lignite react completely when the particle pressure of $\mathrm{O}_{2}$ over $40 \%$.

Fig. 3(a) is an exception curve in which the content of oxygen is $21 \%$, the lowest content of all the condition. There is no overlap curve of the storage lignite with the fresh lignite $320^{\circ} \mathrm{C}$ later, the sample loss its mass slowly and the reaction mass just attach $31 \%$, under the content of moisture volatile matter in the sample. which indicate that the storage sample combustion weakly in the low oxygen level.

It is argued that only particular sites at internal surface coal pores can attract the oxygen molecules when combusting. During stored process, oxygen chemisorptions accompanied with coal surface oxidation and formation of surface oxygen containing less or more stable species. Which reduce the reactive sites of coal in combustion reaction. On the other hand, the internal surface area of coal pores is much larger than the external surface, low temperature oxidation of coal is consider to be a phenomenon occurring predominantly at the internal surface of coal pores ${ }^{20-23}$. Owing to coal oxidation, the internal surface area of coal particle is reduced ${ }^{20,21}$. To prove the result, the specific surface area of storage lignite and fresh lignite is tested by BET method. The result showed that the BET specific surface area of storage lignite is $2.1563 \mathrm{~m}^{2} \mathrm{~g}^{-1}$ while the fresh lignite is $12.6467 \mathrm{~m}^{2} \mathrm{~g}^{-1}$, six times of storage lignite. which indicate that the reaction surface between coal and oxygen is higher than the storage one.

Another explanations of the phenomena is the existence of the pulverized coal in the crucible. The storage lignite had passed through the fragmentation of loss moisture, so the fresh lignite can fragment in the smaller particle in combustion process. The storage lignite packed intense and steadily. The oxygen with low particle pressure difficulty diffuse into the interior of the pile and there are no enough oxygen to make the coal ignite.

DTA profiles of storage lignite and fresh lignite: It is known that the exothermic reactions attribute to the oxidation reaction of heterogeneous organic matter in the coal samples. The differential thermal analysis (DTA) profile are shown in Fig. 4(a-b), The peak of the exothermic reaction region shifts to lower temperatures and gets sharper.

As can be seen from Fig. 4(a) that the exotherm curves are not smooth and the amplitude fluctuate strongly,which demonstrate that the reactive process is not stable. the endothermic reaction happened after $700{ }^{\circ} \mathrm{C}$ in $21 \% \mathrm{O}_{2}$ and $80 \%$ $\mathrm{O}_{2}$ atmosphere.

Fig. 4(b) shows the DTA curves of fresh lignite which are smoothly, then demonstrate that the reactive process is stable. The curve shows two exothermic peak in all atmosphere, the 

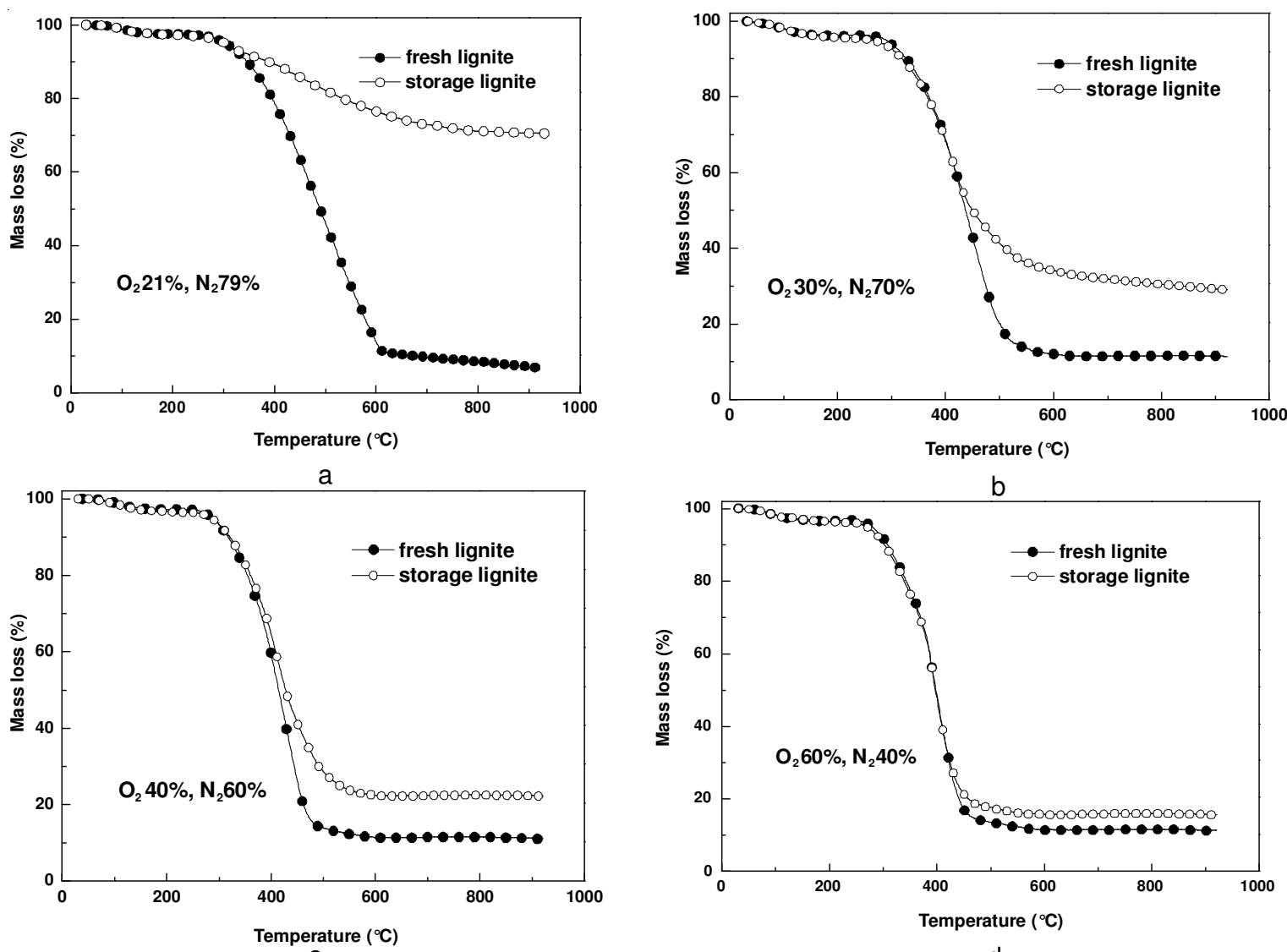

d

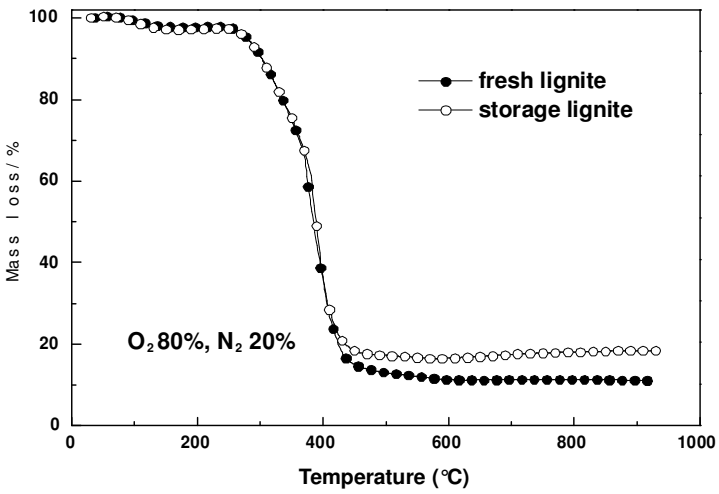

Fig. 3. Comparation of TG profiles of Huolinhe storage lignite and Huolinhe fresh lignite in each $\mathrm{O}_{2}$ particle pressure

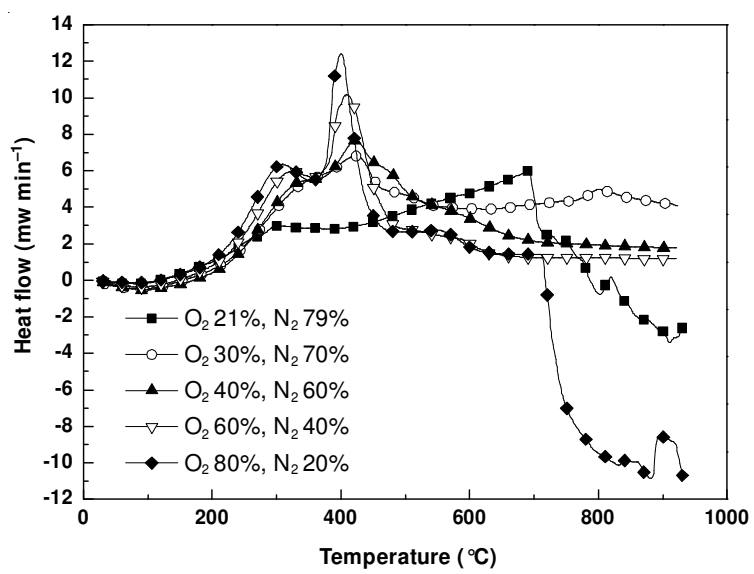

(a) storage lignite

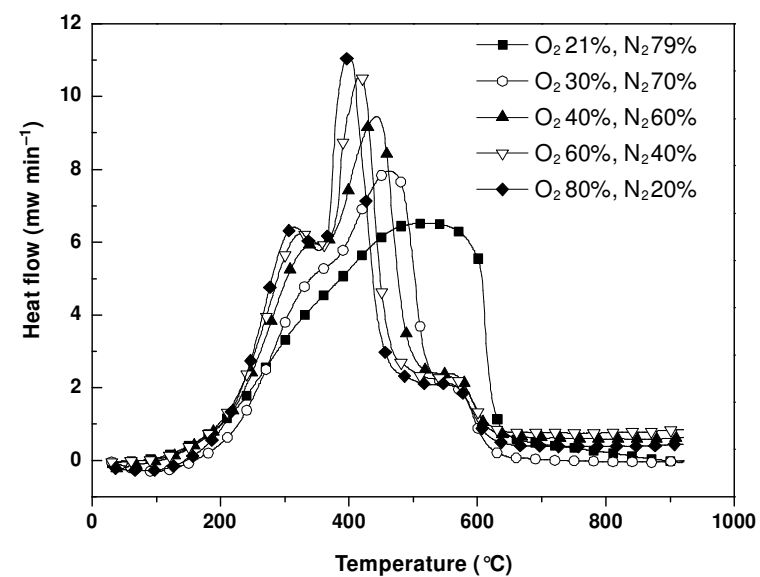

(b) fresh lignite

Fig. 4. DTA profiles of Huolinhe storage lignite and Huolinhe fresh lignite in oxygen-enriched atmosphere 

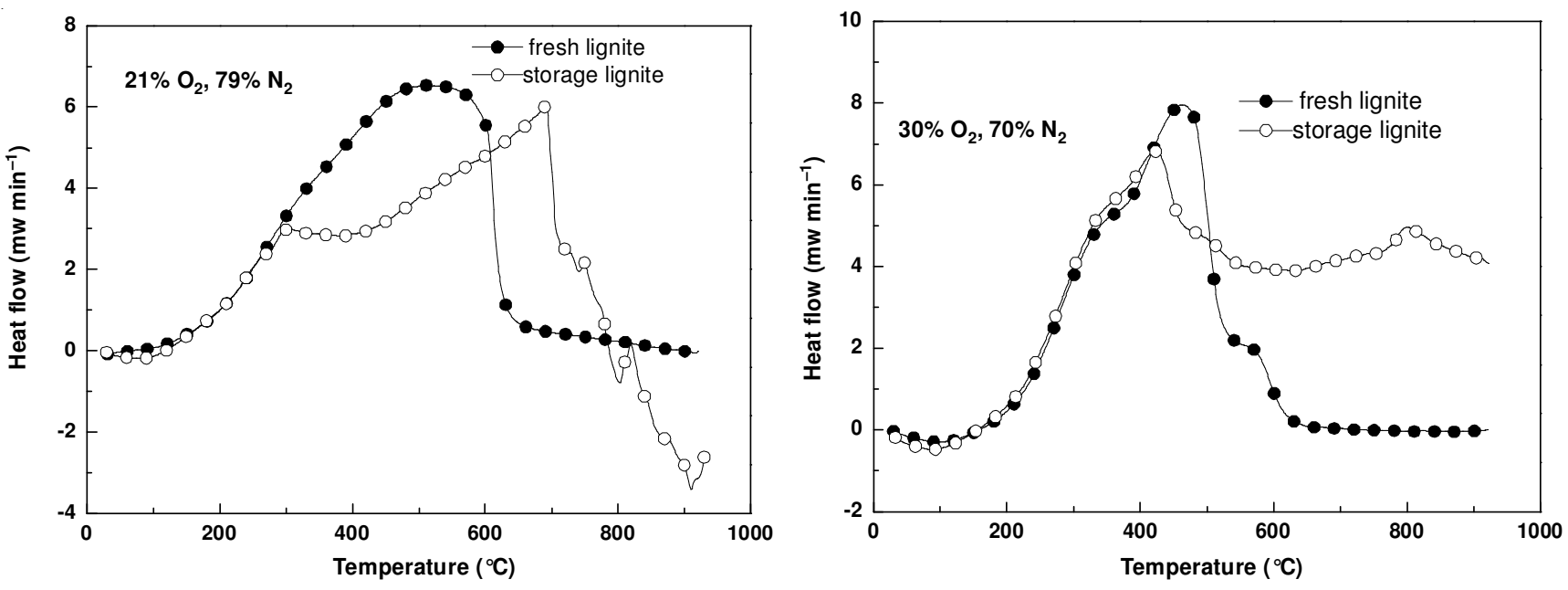

a

b
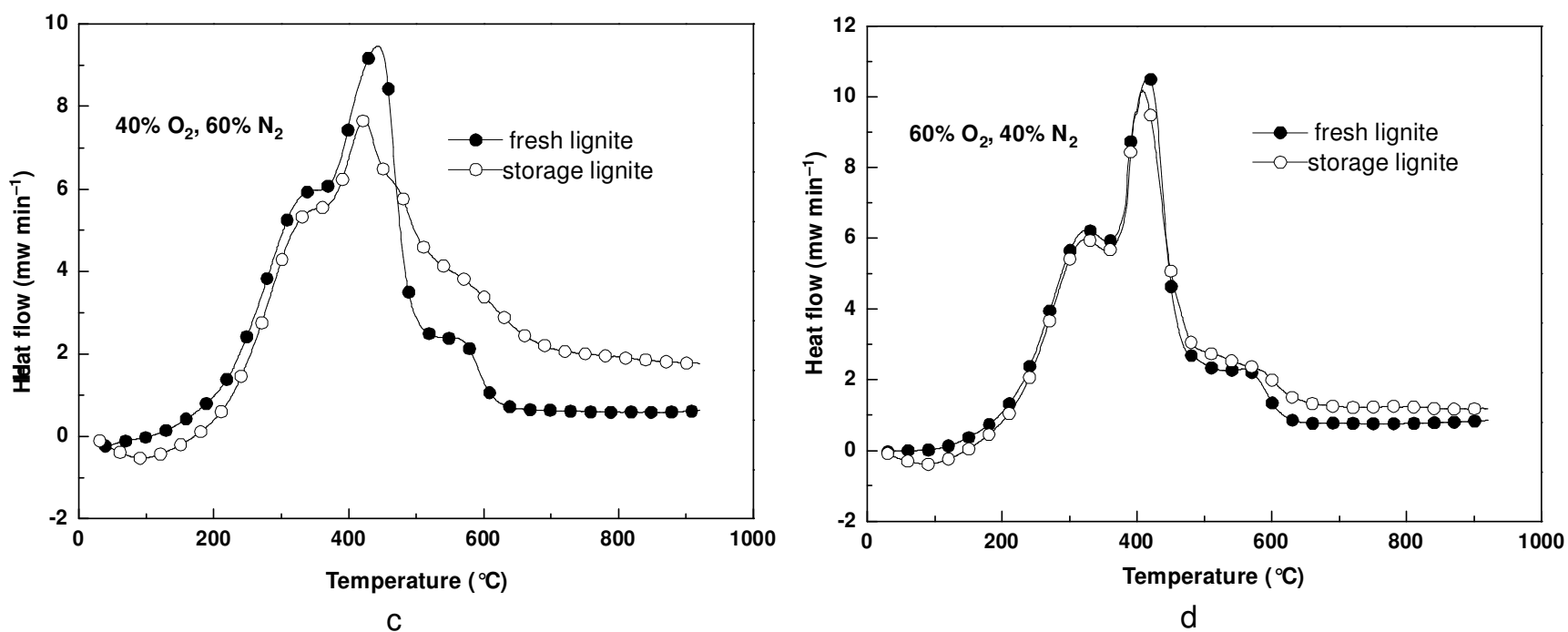

C

d

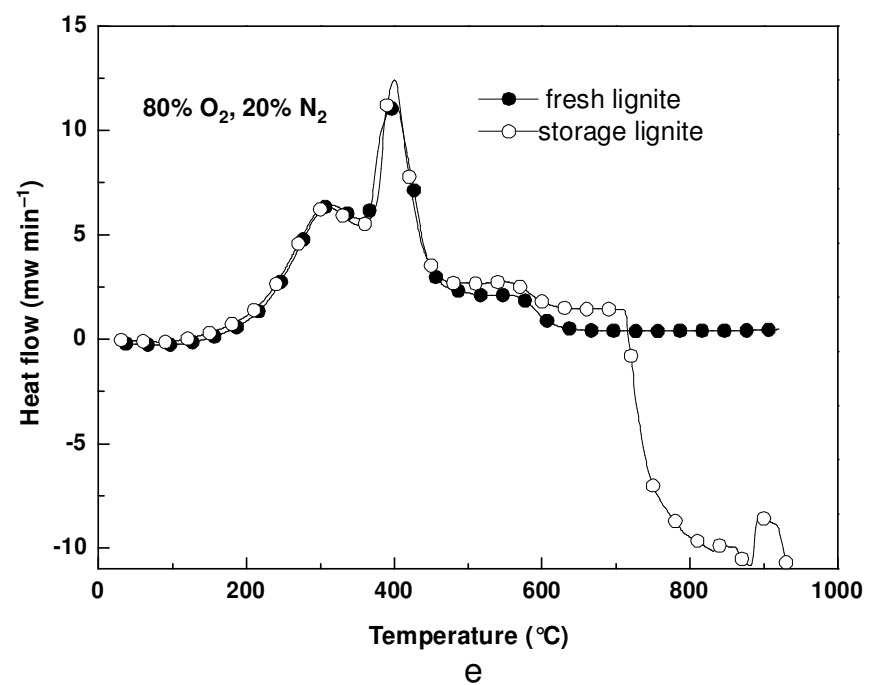

Fig. 5. Comparation of DTA curve between storage lignite and fresh lignite in different atmosphere

first attribute to pyrolysis while the second exothermic peak depend on the combustion ${ }^{23}$.

Fig. 5(a-e) compared the DTA curves of fresh lignite with the curve of storage lignite, Fig. 5(b) and 5(c) appeared that the storage sample exothermic incomplete in comparison with the fresh lignite. Fig. 5(d) and 5(e) showed that the curve of storage lignite curve is almost coincided with that of the curve of fresh lignite, which indicate that the storage sample exothermic completely compared with the fresh lignite. A particular phenomena is that endothermic reaction happened after $700{ }^{\circ} \mathrm{C}$ in $80 \% \mathrm{O}_{2}$ and $21 \% \mathrm{O}_{2}$ conditions, the phenomena produced by minute quantity humic acid degradation endothermic process. 
Fig. 5(a) is an exception curve in which the oxygen concentration is $21 \%$, the curve of the storage lignite and the fresh lignite are not overlap after $300{ }^{\circ} \mathrm{C}$, which is the ignition temperature of the fresh sample. Then the exothermic peak of storage lignite shift to high temperature zone in proportion to fresh lignite. In addition, endothermic reaction appear after $700{ }^{\circ} \mathrm{C}$. The storage lignite ignition until $400{ }^{\circ} \mathrm{C}$, then burn slowly and weakly.

It was observed that a oxidized coal consumes oxygen at a rate far lower than a freshly coal in low temperature oxidation of coal, generating unstable solid intermediate carbon-oxygen complexes, which then decompose into gaseous products $(\mathrm{CO}$, $\mathrm{CO}_{2}$ ) and stable solid complexes. At the accelerated oxidation stage, the stable complexes begin to decompose in large amounts and provided new active sites for further oxidation ${ }^{17}$. Combined with the results of functional group testing and BET testing can ensured that the storage lignite was oxygenated in low temperature because of long-term storage. From TG profiles and DTA profiles, put forward ideas that the ability of oxygenated lignite combination with oxygen decreased on the shallow surface of lignite, it is difficult for persistent reaction. During improve the oxygen particle pressure, oxygen diffused widely and deeply in the surface of lignite and combination with the unoxidized active site. Then increase chances of combination with oxygen, the combustion reaction goes easily.

\section{Conclusion}

In the present study, TG/DTA method were adopted to investigate the combustion property of long-term storage lignite in enriched oxygen atmosphere. The concentration of oxygen in the range of $21 \%$ to $80 \%$. The general conclusion draw from the results of this work were as follows:

The long term storage make the lignite oxidized that cause the absorption peak of hydroxyl groups in functional groups disappeared or decrease. And surface area reduced. The combustion ability of long-term storage lignite weaken in air atmosphere, sometimes can't combustion completely. Oxygenenriched method can improve the combustion ability of storage lignite. The combustion residual solid reduced by $38.8 \%$ in $30 \% \mathrm{O}_{2}$ atmosphere compared with air atmosphere. When the concentration of oxygen above $40 \%$, the sample combustion completely.

\section{ACKNOWLEDGEMENTS}

This work is financially supported by the National Natural Science Foundation of China(21066009), Scientific and Technological Project of Inner Mongolia (20080404ZD01) and New Century Excellent Researcher Award Program from Ministry of Education of China (NCET:2009-09-0865) and Project of Inner Mongolia Education Department (NJ09071).

\section{REFERENCES}

1. P.J. Ashman and P.J. Mullinger, Fuel, 84, 1195 (2005).

2. Y.B. Tang, Z.H. Li, Y.L. Yang, N. Song and D.J. Ma, Asian J. Chem., 25, 441 (2013).

3. J.J. Pis, G. de la Puente, E. Fuente, A. Morán and F. Rubiera, Thermochim. Acta, 279, 93 (1996).

4. K. Baris, S. Kizgut and V. Didari, Fuel, 93, 423 (2012).

5. H.H. Wang, B.Z. Dlugogorski and E.M. Kennedy, Prog. Energy Combust., 29, 487 (2003).

6. R.E. Jones and D.T.A. Townend, Nature, 155, 424 (1945).

7. R.E. Jones and D.T.A. Townend, J. Soc. Chem. Ind., 68, 197 (1949).

8. F.E. Huggins and G.P. Huffman, in ed.: C.R. Nelson, Chemistry of Coal Weathering, vol. 14, Ch. 3, Amsterdam, p. 33 (1989).

9. Q.B. Wang, X.L. Zhang, D.P. Xu and Q.R. Chen, J. China Univ. Mining Technol., 17, 495 (2007).

10. G.H. Wang and A.N. Zhou, Int. J. Mining Technol., 22, 517 (2012).

11. Y.S. Nugroho, A.C. McIntosh and B.M. Gibbs, Fuel, 79, 1951 (2000).

12. H. Wang, B.Z. Dlugogorski and E.M. Kennedy, Combust. Flame, 134, 107 (2003)

13. A. Küçük, Y. Kadioglu and M.S. Gülaboglu, Combust. Flame, 133, 255 (2003)

14. J. Krzywanski, T. Czakiert, W. Muskala, R. Sekret and W. Nowak, Fuel Process. Technol., 91, 290 (2010).

15. J. Krzywanski, T. Czakiert, W. Muskala, R. Sekret and W. Nowak, Fuel Process. Technol., 91, 364 (2010).

16. Z.S. Yu, X.Q. Ma and Y.F. Liao, Renew. Energy, 35, 895 (2010).

17. L.Q. Yin, Coal Sci. Technol., 32, 12 (2004).

18. Q.L. He, K.B. Ren and D.M. Wang, Coal Eng., 11, 45 (2003).

19. Z. Xu and D.Y. Cao, Coal Geology Chin., 20, 5 (2008).

20. D.L. Carpenter and G.D. Sergeant, Fuel, 45, 429 (1966).

21. O.P. Mahajan and J.P. Walker Jr., Fuel, 50, 308 (1971).

22. H. Gan, S.P. Nandi and J.P. Walker Jr., Fuel, 51, 272 (1972).

23. R. Kaji, Y. Hishinuma and Y. Nakamura, Fuel, 64, 297 (1985). 